\title{
DISCUSSÕES SOBRE IDENTIDADE DE GÊNERO E AS TENSÕES NO AMBIENTE ESCOLAR
}

\author{
DISCUSSIONS ON GENDER IDENTITY AND TENSIONS IN THE \\ SCHOOL ENVIRONMENT
}

\author{
Rosana N. M. Ferreira ${ }^{1}$ \\ Karen Franklin ${ }^{2}$
}

Recebido em: 08/2020

Aprovado em: 08/2020

\begin{abstract}
Resumo: O presente artigo aborda diferentes concepções sobre as teorias de formação da identidade, discutindo suas implicações nas propostas de políticas públicas para a educação. Nesse intuito, a apresentação da questão de forma panorâmica é fundamental, pois demonstra que não há apenas uma abordagem da questão. A discussão parte da perspectiva filosófica, mas inclui outras contribuições igualmente importantes, como das áreas da neurologia, psicologia, teologia, biologia e antropologia. A temática da identidade não se restringe apenas a uma perspectiva do humano, logo as discussões perpassam as múltiplas visões que tornam a temática da identidade uma questão do agora. A primeira parte aborda a questão da manutenção da liberdade de divergir, através da legitimação da discordância diante dos problemas enfrentados pelos educadores. A segunda parte apresenta cinco concepções sobre a formação da identidade, a saber: a perspectiva da construção social; a performance de gênero; o uniessencialismo de gênero; o determinismo biológico; e, perspectiva cristã da identidade. Para finalizar, apresenta-se o problema da escolha da perspectiva identitária nos referencias para a educação e suas possíveis consequências políticas e sociais. A problemática da opção unilateral feita pelo Estado brasileiro gera conflitos internos e externos ao ambiente escolar. Assim, a reflexão final, sob a teoria de John Rawls, busca abrir a perspectiva sobre como uma sociedade justa pode observar os princípios que garantem a liberdade individual, a justiça e a igualdade de condições para todos.
\end{abstract}

Palavras-chave: Conceitos de identidade. Gênero. Educação. Políticas públicas.

\begin{abstract}
This article discusses different conceptions of identity formation theories, discussing their implications for public policy proposals for education. In this sense, presenting the question in a panoramic way is fundamental, as it demonstrates that there is not only an approach to the question. The discussion starts from a philosophical perspective, but includes other equally important contributions, such as from the areas of neurology, psychology, theology, biology and anthropology. The theme of identity is not restricted to a human perspective only, so the discussions pervade the multiple views that make the theme of identity a question of the now. The first part addresses the issue of maintaining the freedom to differ, by legitimizing the disagreement in the face of the
\end{abstract}

\footnotetext{
${ }^{1}$ Licenciada em Pedagogia. Professora dos anos iniciais do ensino fundamental da Rede Municipal de Curitiba. Especialista em Alfabetização e Filosofia da Educação. Mestranda em Filosofia / UFPR. E-mail: rosana_leader@hotmail.com

${ }^{2}$ Doutora em Filosofia (2004), com pós-doutorado em Filosofia (2013) e Filosofia da Educação (2019), professora da Universidade Federal do Paraná (UFPR). E-mail: karenfranklin@ufpr.br
} 
problems faced by educators. The second part presents five conceptions about the formation of identity: the perspective of social construction; gender performance; gender uniessentialism; biological determinism; and, Christian perspective on identity. Finally, the problem of choosing the identity perspective show in the references for education and its possible political and social consequences. The problem of the unilateral option made by the Brazilian State generates internal and external conflicts in the school environment. Thus, the final reflection, under the theory of John Rawls, seeks to open the perspective on how a just society can observe the principles that guarantee individual freedom, justice and equal conditions for all.

Keywords: Identity concepts. Gender. Education. Public policy.

\section{Introdução}

A temática da identidade de gênero faz parte dos currículos escolares, aparecendo, por vezes, também como conteúdo transversal. Nesse sentido, tal temática no ambiente escolar está imersa de imposições, retaliações, contradições, avanços e retrocessos. Diante das incontáveis polêmicas que o assunto apresenta, seja na fala de especialistas, seja na compreensão de pais, alunos e gestores, busca-se aqui apresentar um panorama das principais teorias, suas críticas e contraposições, contribuindo para o esclarecimento do tema no ambiente da escola. Abordar esse tema é urgente tanto para desmistificar concepções que se apresentam como 'corretas', 'progressistas', 'retrógradas' ou 'conservadoras', como para refletir sobre costumes, cultura popular e acadêmica. Com isso, ao apresentar a temática em três partes, busca-se colocar a discussão em movimento. A primeira parte objetiva apresentar algumas concepções de identidade e discutir sua conceituação. A segunda parte apresenta uma série de abordagens teóricas que discutem o tema através de cinco concepções do problema. A primeira abordagem se refere a perspectiva da construção social, onde Simone de Beauvoir é a principal pensadora; a segunda perspectiva é a da performance de gênero, em que Judith Butler e Monique Witting são o referencial bibliográfico; a terceira abordagem é do uniessencialismo de gênero, apresentado por Charlote Witt; a quarta abordagem é apresentada por Baron-Cohen, que busca justificar o determinismo biológico da identidade; e, por fim, a perspectiva cristã da identidade de gênero que está comumente impregnada na cultura brasileira, apresentada por Giuseppe Versaldi e Angelo Vincenzo Zani. Para findar a argumentação, a reflexão sobre o consenso sobreposto de John Rawls busca contribuir para a acomodação das perspectivas e estabelecer o limite da concepção do Estado sobre identidade de gênero a partir das liberdades individuais. Se a escola é um lugar para a reflexão e a discussão de perspectivas de mundo, também é para as perspectivas e visões sobre a identidade dos humanos. 


\section{Escola pública: o campo de batalha das narrativas sobre identidades de gênero.}

Diante de questões complexas em relação a concepção de pessoa, diversidade de crenças, ideologias e expectativas distintas quanto a formação educacional dos jovens, as escolas buscam promover o ensino a partir da atuação de diferentes personagens, como professores, alunos e familiares. Em um momento em que a sociedade discute sobre os paradigmas para abordagem nas questões de identidade de gênero, os atores que trabalham no ambiente escolar podem sentir-se desorientados e inseguros para lidar com situações moralmente conflitantes. No interior de uma escola pode-se perceber essa sensação de insegurança, seja por parte de educadores, por gestores, pais ou alunos. Como abordar a noção de identidade do corpo com crianças da educação infantil e anos iniciais do ensino fundamental? O educador deve prescrever o que o Estado determina ou o que ele mesmo pode defender? É possível deixar essa questão para currículos escolares ou deve-se conformar com a cultura? Ao se afirmar que certas atitudes, palavras ou formas de pensar são predominantemente masculinos ou femininos, geralmente se enfrenta oposição de pais, supervisores ou colegas de trabalho. Da mesma forma, quando se afirma para os estudantes, não haver hábitos exclusivos de um determinado gênero, as reações são semelhantes e o educador enfrenta questionamentos, julgamentos e até repreensões devido à sua posição. Portanto, percebe-se que os profissionais da educação básica, onde as primeiras noções de identidade são concebidas e solidificadas, estão sob um "fogo cruzado" teórico, ou seja, são eles que lutam nesse campo de batalha teórico e moral no qual a cultura brasileira está submetida. Portanto, refletir sobre as diferentes concepções de identidade se apresenta como urgente a esses educadores.

O problema ético aparece, mais claramente, quando os profissionais da educação ensinam crianças pequenas, que ainda não são responsáveis nem tem total capacidade de discernimento. Tais conflitos se evidenciam quando o educador deve escolher a concepção em que o assunto deve ser abordado: a sua própria concepção, a concepção curricular ou a concepção dos pais? Diversas questões morais e de valores geram conflitos entre os responsáveis pela educação das crianças, seja entre pais e escola, seja entre professores e gestores, pois muitas das questões envolvem costumes e tradições relativas ao gênero, costumes aceitos historicamente e que hoje estão sendo questionados na sociedade. Exemplo desse conflito e referente a uma política educacional específica para a questão de identidade de gênero, foi o material que seria distribuído pelo Ministério da Cultura visando atender políticas de inclusão, apelidado de "kit gay", que sem ao menos ter chegado as escolas já convulsionou 
o país ${ }^{3}$.

O reconhecimento se tornou questão essencial para a legitimação da identidade de gênero. No entanto, é preciso constatar que é muito improvável que as diversas esferas da sociedade, destacando-se a religiosa e os movimentos LGBTI+, cheguem à unanimidade sobre a legitimação de concepções identitárias que requerem aceitação social ou de grupo de modo irrestrito. Nesse sentido, a apresentação e discussão de teorias e suas argumentações buscam fundamentar a legitimação da discordância sobre a concepção de identidade de gênero. Intenciona-se referendar o termo legitimação da discordância, para expressar um tipo de acordo coletivo ou uma consciência social que permita a convivência ou pelo menos, coexistência pacífica entre pessoas com questões identitárias inegociáveis para si e que conflitam com valores inegociáveis de outros. O que pode ser fundamentalmente compreendido é que pessoas com questões identitárias pessoalmente inegociáveis, possam estar socialmente legitimadas se essa expressão da liberdade não ferir a liberdade outras pessoas. Nesse sentido, a abordagem de John Rawls sobre o consenso sobreposto (overlapping consensus) sai do campo político da fundamentação teórica da origem da sociedade e é ajustado para responder a uma necessidade do campo moral das identidades de gênero. A eleição dos princípios fundamentais de uma sociedade democrática passa a ser modelo para ajustar narrativas e discursos sobre identidade no interior das escolas. Com isso, a utilização da ideia do consenso sobreposto permitirá compreender como é possível moral e legislativamente permitir o pluralismo de ideias, que mesmo na divergência poderá alcançar uma certa estabilidade e equidade de discursos na unidade da escola. Certamente, conta-se com a capacidade de reconhecimento público de uma concepção razoável de justiça, que tem seus valores sempre em revisão, assegurando assim a coexistência de concepções religiosas, filosóficas e morais abrangentes no ambiente escolar.

\section{As teorias sobre identidade de gênero e suas contraposições: de Simone à Eva.}

Em O Segundo Sexo (1949), Simone de Beauvoir apresenta argumentos e analises que são referências para o movimento feminista contemporâneo. A obra discute a situação da mulher do nascimento até a velhice diante da realidade existencial que a circunda. Descreve

\footnotetext{
3 Projeto "Escola sem Homofobia" do MEC (2004) buscou construir material que abordasse o tema com investimentos de R \$1.9 milhão de reais, através de convênio com o FNDE. Objetivou viabilizar a formação de professores e a distribuição de material, sem acordo com a sociedade o projeto foi rejeitado em 2011. Porém, o material elaborado pela Associação Brasileira de Lésbicas, Gays, Bissexuais, Travestis e Transexuais (ABGLT) foi divulgado na WEB na intenção de auxiliar pais e educadores.
} 
como as condições sociais influenciam e criam o "eterno feminino" esperado de toda mulher e mostra, no decorrer de sua argumentação, como a mulher é colocada como o Outro nas relações humanas. Beauvoir se preocupa em entender a sujeição da mulher à determinação da espécie e afirma que o corpo da mulher é um dos elementos fundamentais para a situação desta no mundo. Apenas seu corpo não bastaria para defini-la, só teria realidade se assumido pela consciência através das ações e inserido em uma sociedade. Sua pergunta essencial é: por que a mulher é o Outro? Simone de Beauvoir quer saber como a natureza da mulher foi construída através da história, ou seja, busca esclarecer o que a humanidade fez da mulher.

Essas questões são pertinentes para a discussão sobre a condição histórica de inferioridade social da mulher em relação ao homem. Sua argumentação reflete sobre as certezas estabelecidas quanto a feminilidade e masculinidade, permitindo rever práticas e discursos usados com estudantes, tais discursos estão presentes em seu cotidiano, onde é possível questionar expectativas e objetivos avaliativos, liberdades e limites estabelecidos para si mesmo e para os próprios estudantes. Tais questões motivaram a mudança de paradigma acerca da concepção sobre a formação da identidade de gênero, apontando que esta não seria uma realidade dada, mas sim uma realidade passível de construção.

Beauvoir busca responder seus questionamentos analisando dados da biologia, psicologia, história, narrativas dos mitos (literatura), da formação e da situação da mulher (esposa, mãe, prostituta). Conclui falando sobre a mulher independente e faz uma crítica importante as mulheres de sua época, que a ideia de liberdade estava amortecida no computo social. Suas críticas podem fazer refletir também a mulher pós-moderna, com todos seus dilemas existenciais e sociais. Por isso, rever as relações de gênero e educação da mulher na perspectiva Beauvoiriana, ainda se apresenta como fundamental para as reflexões e questões que floresceram no século XXI.

É importante ter presente que a autora argumenta a partir de uma concepção existencialista de mundo, portanto pressupõe que a existência precede a essência, ou seja, a partir do nascimento é que o ser construiria sua essência, aquilo que constituirá sua subjetividade, seus limites morais e suas possibilidades existenciais. Essa concepção é fundamental em seu pensamento, pois se não há nada que referencie o ser antes de sua existência, este estaria desamparado e seria preciso ter consciência desse desamparo para que seja possível se tornar o criador de seu próprio destino. Nesse sentido, 
uma liberdade humana: a do criador. É preciso, primeiramente, se colocar sem equívoco como uma liberdade, para alimentar tal pretensão. As restrições que a educação e os costumes impõem à mulher limitam seu domínio sobre o universo. Quando o combate para conquistar um lugar neste mundo é demasiado rude, não se pode pensar em dele sair; ora, é preciso primeiramente emergir dele numa soberana solidão, se se quer tentar reapreendê-lo: o que falta primeiramente à mulher é fazer, na angústia e no orgulho, o aprendizado de seu desamparo e de sua transcendência (BEAUVOIR, 2016, p. 536, vol. II).

Como se vê, um princípio fundamental a ser apreendido por aquelas que desejam superar as restrições da educação e dos costumes, segundo Beauvoir, é libertar-se da mentalidade historicamente posta. E uma das concepções históricas a ser superada seria a concepção de masculinidade e feminilidade limitadas pelos costumes e tradições. Beauvoir enfrenta a questão histórica da concepção da essência das mulheres, a saber, sua feminilidade, através das críticas à perspectiva do poeta Montherlant, que em suas obras de 1936 expunha a essência feminina sempre em oposição à masculinidade. O Romancista mantém a perspectiva conceitual que Simone de Beauvoir considera inapropriada, pois exige da mulher algo externo a ela. A crença "nesta obscura e irredutível essência: a feminilidade", remonta à Antiguidade, onde os conceitos do feminino são negativos. A argumentação de Aristóteles e Tomás de Aquino, apresenta a mulher de forma negativa, pois "a mulher é mulher por falta de virilidade; é o destino que todo indivíduo do sexo feminino deve suportar sem poder modificá-lo" (Beauvoir, 2016, p. 272 vol. I). Ao discutir a infância e a formação da subjetividade a pensadora diz que "entre meninos e meninas, o corpo é, primeiramente, a irradiação de uma subjetividade" (Beauvoir, 2016, p.11, vol. II), portanto, ambos teriam os mesmos instrumentos para compreensão do mundo, sendo os olhos, as mãos e não os órgãos sexuais que apreenderiam o universo. Para ela, são os adultos que lançam o significado nos órgãos sexuais da criança, comprovando através do exemplo do pai que leva o menino ao banheiro e diz "vou lhe mostrar como fazem os homens" e então, o menino se orgulha de ter sido distinguido e iniciado pelo pai. Em contrapartida, as meninas não teriam seus genitais louvados por suas mães, pois elas não as deixam pegar ou ver, seus órgãos genitais devem ser escondidos de si mesmas e dos outros. A autora diz que a menina não sente a ausência do pênis como falha; "seu corpo é evidentemente uma plenitude para ela, mas ela se acha situada no mundo de um modo diferente do menino e um conjunto de fatores pode transformar a seus olhos a diferença em inferioridade" (Beauvoir, 2016, p. 16, vol. II). Nesse sentido, é possível compreender como a teoria de identidade de gênero como construção social se fundamenta na obra de Simone de Beauvoir, mas que certamente não se resume a ela. Essa construção social pode determinar papeis superiores e inferiores, que não estão previamente 
acertados entre os participantes, por isso é preciso refletir sobre os conceitos sociais oriundos dessa posição.

Em Problemas de Gênero: feminismo e subversão da sexualidade (2003), a feminista Judith Butler apresenta sua argumentação referente ao problema da opressão que mulheres e homens homossexuais sofrem por não terem suas identidades politicamente legitimadas. Butler parte da premissa que a identidade, ou melhor, que as categorias de identidade são resultado de instituições, como o falocentrismo e a heterossexualidade, que estão em prática e dos discursos. Diante desse problema, a teórica propõe uma estratégia diferente para a pesquisa feminista, pois

[...] já não está claro que a teoria feminista tenha que tentar resolver as questões da identidade primária para dar continuidade à tarefa política. Em vez disso, devemos nos perguntar que possibilidades políticas são consequência de uma crítica radical das categorias de identidade? Que formas novas de política surgem quando a noção de identidade como base comum já não restringe o discurso sobre políticas feministas? E até que ponto o esforço para localizar uma identidade comum como fundamento para uma política feminista impede uma investigação radical sobre as construções e as normas políticas da própria identidade? (BUTLER, 2003, p. 9).

Observa-se que para apreender a visão Butleriana sobre a concepção de identidade, antes é necessário ter presente a concepção filosófica inaugurada por Wittgenstein de que o uso das palavras determina seu significado. Essa concepção foi posteriormente explorada e ampliada por J. L. Austin com a publicação, em 1962, da obra How to do things with words, que discorre sobre o que pode ser feito com as palavras. Sua teoria, assim como a de Wittgenstein, se opõe à então tradicional teoria da linguagem. A tese gira em torno da possibilidade de três formas de declarar uma sentença, quais sejam, a forma declarativa, a forma constatativa e a forma performativa. A grande novidade inaugurada por Austin foi perceber e sistematizar a forma expressiva performativa a qual trata de enunciados que "não constatam fatos ou ações, mas antes eles mesmos executam uma ação, fazem parte de uma operação. A própria declaração das palavras, realizada em certas condições, significa a execução de uma ação" (Oliveira, 2005, p. $152)$.

A partir desta perspectiva linguística que o trabalho de Butler se desenvolve, onde a performatividade torna-se o centro da construção da identidade de gênero. No enunciado performativo dizer algo seria equivalente a fazer algo. É de extrema importância para a compreensão dessa perspectiva da linguagem/realidade, pontuar que "não tem sentido por aqui a pergunta a respeito de sua verdade ou falsidade, o que para a tradição era a característica fundamental das sentenças" (Oliveira, 2005, p. 153). O critério a ser observado no uso da 
sentença performativa pode ser considerado a partir de questionamentos como "sob que condições a ação em questão se realiza ou não? Quais exigências devem ser cumpridas para que tais atos, de fato, se realizem? Em que circunstâncias se pode dizer que tais atos não chegam à realização?" O resultado desses questionamentos é o que Austin nomeou de "doutrina dos reveses" dos atos performativos, que diz respeito ao sucesso ou insucesso efetivo da ação pronunciada. Diz que "os reveses dos atos performativos correspondem, portanto, à falsidade dos atos constatativos, só que não se pode esquecer que se trata aqui de uma dimensão diferente' (Oliveira, 2005, p. 153). Entende-se a expressão “dimensão diferente" com respeito à dimensão da linguagem descritiva, que descreve uma realidade essencial e à linguagem performativa, que descreve uma ação que pela repetição é estabelecida como realidade. Nota-se, com isso, que Butler aponta compreender o termo gênero como unicamente pertencente a esfera da linguagem performática e que não apresenta nenhuma relação com a realidade, pois se a identidade de gênero é performatividade construída, o próprio termo é resultado dessa construção.

Observa-se então, que a teoria de gênero butleriana descrita em Problemas de Gênero: feminismo e subversão da sexualidade (2003), não só conceitua uma nova perspectiva de gênero como performance, como também apresenta o seguinte esquema estratégico político de ação dos sujeitos: desconstruir conceitos de gênero institucionalmente estabelecidos; subverter o poder; transgredir restrições; seguir com a crítica radical ao conceito de identidade tradicional e a heteronormatividade compulsória e reconstruir uma nova linguagem identitária a partir da teoria feminista. Com essa proposta, Judith Butler busca estabelecer novos recursos na discussão sobre as teorias feministas, pois busca reconstruir ou estabelecer uma nova fase da discussão sobre identidade.

A proposta de Butler em estabelecer novos recursos discursivos para se pensar as questões de gênero e identidade, recolocam o problema do locus da discussão, se no ambiente acadêmico, político ou religioso, pois a situação social do debate pode determinar acolhimentos e rechaços. Conforme o ambiente social da inserção da discussão, novas instituições linguísticas poderão se tornar normativas ao longo do tempo, no entanto, seriam igualmente construções que visam reafirmar forças e poderes. Não restringir a discussão sobre identidade de gênero a um binômio ou a uma multiplicidade tipificada parece ser uma conquista de Butler, porém a destituição de identidades historicamente constituídas também se tornam problemas sociais específicos quando no ambiente escolar. É nele que múltiplas questões, que por vezes chegam como imposições, se desenvolvem e encontram acolhimentos e rechaços.

Charlotte Witt (2010) avança na questão dos estudos feministas quando retoma o 
problema da essência: você seria a mesma pessoa ou indivíduo se pertencesse a um gênero diferente? Essa questão coloca Witt frente a pessoas que, em grande parte, afirmam que não seriam a mesma pessoa. Tais respostas reafirmam a necessidade de que estudos feministas acolham a questão do essencialismo de gênero e não apenas da perspectiva performática (Butler) ou de construção social (Beauvoir). A autora percebe que o gênero é central na vida social e investigar sobre a questão de gênero é essencial na vida das pessoas, pois o gênero é fator determinante para que certas pessoas considerem que seriam outras, caso tivessem um gênero diferente. Aqui a diferença fundamental com a concepção de Beauvoir se torna importante para o debate. Ao mesmo tempo que Simone de Beauvoir descarta qualquer essência anterior a existência e afirma a necessidade de reconhecer o próprio desamparo para então libertar-se, Charlotte Witt considera o gênero a própria essência dada ao ser, ou seja, aquilo que o indivíduo tem e a partir de onde pode construir-se. Assim, seu interesse vai de encontro a importância do gênero para determinar o indivíduo social, a centralidade do "ser homem" ou do "ser mulher" nas experiências individuais.

O conceito de essencialismo de gênero é bastante controverso entre estudiosos(as) engajados(as) na causa feminista e até mesmo considerado como pouco relevante para os interesses do movimento. No entanto, Witt propôs uma discussão inovadora ao apresentar o conceito de uniessencialismo, em sua obra The Metaphysics of Gender (2010). Ela busca em Aristóteles a base conceitual que fundamenta sua teoria: "eu uso um modelo aristotélico para expressar o essencialismo da unificação (ou uniessencialismo). E eu diferencio o uniessencialismo de outros tipos de visões essencialistas" (Witt, 2011, p. xiii). Ela usa o termo essencialismo da unificação para significar a expressão uniessencialismo, portanto, compreende-se que em seu pensamento, Witt discute que o gênero é essencial para o indivíduo social, ou seja, o gênero só tem função se inserido no social, nas relações e que sua função específica seria a reprodução. Diz que está interessada em saber se o nosso gênero é essencial para nós como indivíduos sociais (Witt, 2011, p. 13). Para explicar sua posição conceitual, ela demonstra que para Aristóteles a essência é a causa de ser do indivíduo, afirma que tanto artefatos quanto indivíduos biológicos têm essências em que ambos têm um princípio que explica sua existência como indivíduos (Witt, 2011, p. 14). Diz que

Artefatos e indivíduos biológicos também são semelhantes porque o princípio que explica sua existência como indivíduos é uma essência funcional. Uma essência funcional é uma propriedade essencial que explica para que serve o indivíduo, qual é o seu propósito e que organiza as partes para esse fim (WITT, 2011, p. 14). (Tradução própria) 
Sua posição sobre a identidade de gênero, considerando a essência dos indivíduos que se identifica no sujeito através de sua função, a saber, a reprodução, coloca na mesa de discussão a diferença entre coisas e humanos. Nos artefatos o propósito é de origem externa, visto que sua função foi determinada pela intenção humana, mas os propósitos do indivíduo são intrínsecos ao organismo (Witt, 2011, p. 14). Esta propriedade da necessidade de reprodução seria a essência individual que torna o indivíduo quem ele é. O gênero é, para Witt, aquilo que explica a existência do sujeito, que o unifica e organiza, o que indica seu propósito social. Nesse sentido ela busca "definir a posição social de ser mulher e ser homem em termos das funções reprodutivas (ou geradoras) socialmente mediadas em que um indivíduo é reconhecido (por outros) para executar"4 (Witt, 2011, p. 18). Ela busca estabelecer as noções de uniessencialismo para tratar a relação que as pessoas têm socialmente, porém isso não significa que as escolhas pessoais e a liberdade, de reproduzir-se ou não, foram reprimidas.

Certamente discutir sob essa perspectiva torna o acolhimento da pesquisa sobre as diferenças entre os sexos, do pesquisador Baron-Cohen (2004), muito importante para tratarmos da questão no ambiente escolar. Ele evidencia que fatores biológicos e não apenas de influências culturais podem determinar a diferença entre os sexos. Nesse sentido, e sob a perspectiva médica admite-se que há um determinismo biológico que dificilmente se poderá desconsiderar. Baron-Cohen desenvolve sua argumentação defendendo a existência de diferentes tipos de cérebro, o tipo $\mathrm{E}$ (empatia) ${ }^{5}$, o tipo $\mathrm{S}$ (sistematização), e o tipo de cérebro B, em que empatia e sistematização se equilibram. Para ele, o cérebro tipo E (empatia) está presente na maioria das mulheres e o cérebro tipo $S$ (sistematização), está presente na maioria dos homens. No entanto, seria perfeitamente comum encontrar mulheres com cérebro predominantemente sistematizados e homens com cérebros predominantemente voltados para a empatia. Baron-Cohen busca referendar sua explanação na pesquisa de Doreen Kimura, que baseou suas investigações em diferenças morfológicas e comportamentais do cérebro. Para Baron-Cohen, há fatores biológicos que influenciados pelos hormônios, criam desde a fecundação condições neurológicas específicas em ambos os sexos. Embora também pondera

\footnotetext{
${ }^{4}$ Texto original: "I propose to define the social position of being a woman and being a man in terms of the socially mediated reproductive (or engendering) functions that an individual is recognized (by others) to perform" (Witt, 2011, p. 18). Traduzido pela autora.

${ }^{5}$ Essa abordagem empática pode ser melhor compreendida quando transferida para a questão educacional no trabalho de Martha Nussbaum, que busca defender uma educação baseada na empatia, no compromisso social e na interação cultural. Ver NUSSBAUM, Martha. Cultivating humanity: a classical defense of reform in liberal Education. Oxford: Oxford University Press, 1997; Educação e Justiça social, Ed. Pedago, 2014.
} 
que "devemos ter o cuidado, é claro, de não presumir que as diferenças sexuais se devam apenas à biologia. Isso seria cometer um erro oposto ao que se viu nos anos 60 , quando se acreditava que todas as diferenças sexuais fossem reflexo da socialização" (Baron-Cohen, 2004, p. 25). Assim, é preciso ter cautela em afirmar uma determinação absolutamente biológica, como da mesma forma uma construção identitária absolutamente social.

A empatia, essa característica tipicamente feminina, segundo Baron-Cohen

Consiste em uma sintonização espontânea e natural com as ideias e sentimentos do outro, quaisquer que sejam eles. Não se trata apenas de reagir a um pequeno número de emoções de alguém, como dor ou tristeza; trata-se de sentir a atmosfera emocional que se instala; de se colocar sem maior esforço no lugar do outro, administrando com sensibilidade uma interação que não machuque nem ofenda sentimentos (BARON-COHEN, 2004, p. 38).

Definir a empatia como a capacidade de interpretar sentimentos e reagir adequadamente a eles se torna uma das características dos cérebros tipo E. Referenda que "em um estudo ${ }^{6}$, [é possível] apresentar que os garotinhos demonstraram 50 vezes mais competição, enquanto as meninas demonstraram 20 vezes mais capacidade de esperar a vez. Estes são exemplos de como a empatia difere de um sexo para outro na vida diária" (Baron-Cohen, 2004, p. 46).

O outro tipo de cérebro que Baron-Cohen analisa é o sistematizador, que é definido como "o impulso de compreender e construir um sistema. O sistema que me refiro é tudo que seja governado pelas regras que especificam a relação entre dado de entrada-operaçãoresultado" (Baron-Cohen, 2004, p. 79). Baron-Cohen descreve a capacidade de sistematização com o seguinte exemplo

Leve um grupo de crianças a partir de oito anos a um local desconhecido, dê a elas um mapa e depois peça que recriem o mapa da área por meio de desenho. As meninas incluem mais elementos da paisagem e o meninos, mais caminhos (estradas, etc.). Se a experiência for repetida com um segundo grupo de crianças, porém com o mapa e o passeio pelo local reduzidos à metade, para dificultar um pouco a tarefa, os meninos ainda assim se lembram melhor das posições relativas dos lugares. Meninos e meninas têm abordagens muito diferentes da tarefa. $\mathrm{O}$ cérebro masculino arruma o elementos em um sistema geométrico ou de rede; o cérebro feminino marca os elementos descritivamente (BARON-COHEN, 2004, p. 97).

Tais constatações são relevantes para um ambiente escolar, especialmente as considerações sobre o tipo de cérebro extremamente sistematizador, que segundo ele está ligado

\footnotetext{
${ }^{6}$ Crombie e Desjardins (1993); Crick e Ladd (1990); Cairns, Cairns, Neckerman et al. Howes (1988).
} 
ao cérebro masculino. Certamente aqui pode-se considerar a referência de sistematização para o caso de autistas. A distinção de como os cérebros percebem a realidade e suas formas é de grande importância para os processos educativos, pois considerar a diferença entre cérebros empáticos, sistemáticos e em equilíbrio pode estar na base da eficiência educacional. Tais evidências podem ser bastante proveitosas para professores que refletem sobre a didática mais adequada para cada tipo de capacidade e funcionamento cerebral. Mas também para compreender como a questão de identidade de gênero pode ser abordada ou igualmente considerada no decorrer da escolaridade. Seria possível relacionar questões educativas aos tipos de cérebros? Seriam meninos e meninas capacitados distintivamente em suas funções cerebrais? A percepção da própria identidade de gênero depende da formação cerebral ou a construção social?

Em junho de 2019 foi publicado, pela Congregação para a Educação Católica, um documento chamado Homem e Mulher os Criou. Para uma via de diálogo sobre a questão do Gênero na educação. Esse texto apresenta a discussão sobre o pensamento da igreja católica sobre a pessoa humana, onde reafirma a unidade de alma e corpo sintetizada no humano frente ao clima cultural de nosso tempo que é marcado por uma carência e desorientação antropológica. O documento indica que a concepção conceitual do ser, na visão cristã, centrase na ligação indissociável da relação do corpo com a identidade essencial do indivíduo, pois "de fato, há argumentos racionais que esclarecem a centralidade do corpo como elemento integrante da identidade pessoal e dos relacionamentos familiares. O corpo é subjetividade que comunica a identidade do ser"7 (Versaldi \& Zani, 2019, p. 13).

Os autores observam que a visão antropológica cristã vê a sexualidade como fundamental e pertencente a personalidade humana, seria um modo de ser, de se manifestar, comunicar-se, sentir, expressar e viver o amor. Nesse sentido, o processo de crescimento desta diversidade, ligada à complementaridade dos dois sexos, responderia plenamente ao plano de Deus. Com isso, a educação afetivo/sexual deve considerar a totalidade da pessoa, ou seja, consideram imprescindível a integração dos elementos biológicos, psicoafetivos, sociais e espirituais.

Os autores argumentam a necessidade de reiterar a raiz metafísica da diferença sexual, onde homem e mulher seriam as duas maneiras pelas quais se expressam e realizam a realidade

\footnotetext{
7 Texto original: "Ci sono, infatti, argomenti razionali che chiariscono la centralità del corpo come elemento integrante dell'identità personale e dei rapporti familiari. Il corpo è soggettività che comunica l'identità dell'essere" (Versaldi \& Zani, 2019). Tradução própria.
} 
ontológica da pessoa humana. Esta seria a resposta antropológica à negação da dualidade masculino/feminino da qual se gera a família. A rejeição desta dualidade teria criado a ideia de uma pessoa abstrata, que poderia escolher para si ser algo independente da sua natureza (Versaldi \& Zani, 2019, p. 19).

A pergunta é, qual seria essa raiz metafísica da diferença entre as identidades masculina e feminina que produziria sua realidade ontológica? A perspectiva cristã toma como axioma a existência de um propósito divino para as pessoas e que esse propósito (ter paz e vida plenas através de Cristo) é realizável através da fé e da consequente restauração da coerência entre as esferas espiritual, biológica e social do indivíduo. Com isso, a masculinidade e a feminilidade seriam aspectos inatos do ser e indissociáveis para o cumprimento de tal propósito. Nesse sentido, a identidade para o cristão estaria ligada ao espírito e a sua semelhança com Deus. A identidade não seria construída apenas psíquica ou culturalmente, nem apenas determinada biologicamente, mas um conjunto de todos esses aspectos com propósitos espirituais. A teoria vaticana busca explicar essa pluralidade de teorias específicas, que surgiram pela perda de referência espiritual dos indivíduos.

Para o cristão, a identidade do Criador está estabelecida desde a eternidade e é imutável. O cristão referenciado em Deus, identifica-se com a essência divina e com seu propósito universal de restauração do relacionamento íntimo e pessoal do humano com seu criador, pois pode ser observado que o drama bíblico desde o gênesis até o advento da encarnação, morte e ressurreição de Cristo, mostra que o propósito do Criador foi criar o ser humano para relacionarse consigo e que este tivesse paz e vida plena. No entanto, essa paz interna advinda de sua ligação íntima com o próprio Deus cessou quando o divino deixou de ser, para homens e mulheres, referência para reconhecer o bem e o mal. A argumentação cristã leva a considerar que a coerência interna do ser humano fracassou a partir de sua rebelião contra o Ser divino que o referenciava, e, esse fato, de estar sem referência, teria gerado uma sucessão infinita de tentativas de construções teóricas a fim de substituir a lei moral divina estabelecida desde a eternidade. Nesse sentido, os defensores da perspectiva cristã sobre a identidade afirmam que a própria Providência estabeleceria o pacto da Cruz, uma forma de redimir sua criação e trazêla de volta para $\mathrm{Si}$, reestabelecendo a comunhão primeira entre Criador e criaturas e consequentemente, também a coerência, equilíbrio e paz interior naqueles que se submetessem a esse pacto. Por isso, o cristão se disporia voluntariamente a certo estilo de vida, valorizando mais a espiritualidade que o corpo, onde buscaria manter o equilíbrio entre seu espírito, corpo e práticas sociais, mesmo que considerasse para si um sacrifício, estaria disposto a submeter- 
se, pois alcançar a plenitude perfeita de vida e paz seria seu objetivo.

No ideal cristão a submissão é um fator espiritual fundamental para homens e mulheres, pois tem em Cristo sua principal referência, começando por Eva. Ambos deveriam submeterse aos princípios bíblicos para o bem da família. Nesse sentido, a desconsideração sobre a dualidade de identidade feminina/masculina e suas funções sociais e espirituais, reinvindicações de construção identitárias sociais ou pela linguagem são encaradas como um entendimento limitado de um contexto mais amplo, regido por leis espirituais eternas. O cristão não deveria agir a partir de estímulos do "proibido" ou por impulsos recalcados, mas sim a partir do chamado divino para o cumprimento de seu propósito, essa seria uma atitude voluntária, de entrega pessoal a uma vida de mortificação do corpo, em benefício eterno de seu espírito.

Pode-se notar que a multiplicidade de posições sobre a identidade de gênero e identidade do humano são discutidas em campo aberto. As demandas são por reconhecimento social, espiritual e individual, onde a estruturação do poder e das instituições tem forte influência. As teorias divergentes sobre a identidade de gênero parecem de grandes proporções e de difícil acolhimento dentro da possibilidade de um consenso, seja no ambiente social, seja no ambiente escolar. Certamente, urge a discussão sobre a identidade de gênero por parte de diferentes setores da sociedade, onde deveria estar garantida a liberdade de divergir. Porém, onde, como e em qual sentido a questão é debatida reflete no ambiente escolar, por vezes, de forma violenta, pois são as políticas públicas para a educação que determinam e garantem a liberdade de discutir concepções de identidade de gênero na escola. A questão sempre aparece: É o Estado que deve determinar quais teorias sobre identidade de gênero devem ser acolhidas na escola ou são os particulares?

\section{Os conceitos de formação da identidade na educação: um olhar sobre os documentos que regram a educação brasileira.}

A Secretaria Municipal de Educação do Município de Curitiba tem formulado seus documentos referenciais tendo o cuidado de dialogar com a Agenda 2030 da ONU. Sendo assim, instituiu seu programa de formação de professores considerando os Objetivos de Desenvolvimento Sustentável (ODS) como base de todas as suas proposições formativas e também, incentiva os profissionais a ecoarem tais metas em suas práticas afirmando que 
Atualmente, todas as opções formativas da SME contemplam um ou mais Objetivos do Desenvolvimento Sustentável, esse respaldo vislumbra o engajamento das unidades escolares e de seus profissionais para que a Agenda 2030 seja pensada, planejada e efetivada localmente em cada unidade. Esse engajamento local reverbera globalmente, compreendendo que o desenvolvimento global está intimamente relacionado a cada ação local. As ações da SME voltadas para a efetivação da Agenda 2030 são fundamentais, pois o processo educativo atinge a toda uma comunidade escolar profissionais da educação, crianças, estudantes e familiares. Assim, quando uma ação formativa aborda e problematiza cada um dos ODS, esses conceitos são discutidos para além do ambiente educativo, mas avançam para o cotidiano da cidade (CURITIBA, 2019, p. 10).

Entre os 17 objetivos propostos na Agenda 2030, está o objetivo número 5 que se refere a igualdade de gênero e tem como meta alcançar a igualdade de gênero e empoderar todas as mulheres e meninas. Um dos documentos referenciais da ONU é o Glossário de termos do Objetivo de Desenvolvimento Sustentável 5, que indica e define conceitualmente a perspectiva de formação de identidade que permeia suas propostas de ações políticas para as nações, descrevendo que o termo gênero se refere

[...] a papéis, comportamentos, atividades e atributos que uma dada sociedade em um dado momento considera apropriado para homens e mulheres. Além dos atributos sociais e oportunidades associadas com ser homem ou mulher e as relações entre mulheres e homens, meninas e meninos, o gênero também se refere às relações entre mulheres e aquelas entre os homens. Estes atributos, oportunidades e relações são socialmente construídas e são aprendidas por meio de processos de socialização. Elas são específicas a um contexto e a um tempo, bem como são mutáveis (ONU BRASIL, 2016). (Grifo nosso)

Assim, percebe-se que a perspectiva da Organização das Nações Unidas, que consequentemente também é assumida pela Rede Municipal de Educação, concebe que a identidade de gênero é constituída através da construção social, que atributos identitários e relações são construídos socialmente e passíveis de mudanças. O documento da ONU é claro em proferir a tese de que o ser homem e mulher é referente a uma construção social, não há, no documento, reflexões ou ponderações sobre a liberdade de pensamento e diversidade conceitual sobre o assunto. Assim, não apenas a SME de Curitiba adota essa terminologia, mas também uma infinidade de outros agentes públicos no Brasil e no mundo.

O Plano Nacional de Educação em Direitos Humanos afirma que "a escola é local de estruturação de concepções de mundo e de consciência social, de circulação e de consolidação de valores, de promoção da diversidade cultural” (Brasil, 2007, p. 31). Esse documento referencial reconhece que "o processo formativo pressupõe o reconhecimento da pluralidade e 
da alteridade, condições básicas da liberdade para o exercício da crítica, da criatividade, do debate de ideias e para o reconhecimento, respeito, promoção e valorização da diversidade" (Brasil, 2007, p. 31). Diz também que "a escola, como espaço privilegiado para a construção e consolidação da cultura de direitos humanos, deve assegurar que os objetivos e as práticas a serem adotados sejam coerentes com os valores e princípios da educação em direitos humanos" (Brasil, 2007, p. 32). Dentre os diversos princípios norteadores que o texto apresenta, o primeiro diz que "a educação deve ter a função de desenvolver uma cultura de direitos humanos em todos os espaços sociais" e mais adiante recomenda que a equidade de gênero seja assegurada (Brasil, 2007, p. 32). Este documento assevera que a perspectiva de gênero a ser considerada é a da construção social. Nesse sentido, temos uma opção teórica por parte do Estado, mas quais implicações a perspectiva unilateral sobre a formação da identidade, em tais documentos, traria para a comunidade escolar?

Visto que todas as práticas escolares devem estar de acordo com a educação em direitos humanos, os demais documentos referenciais e regulatórios também reproduzem em cadeia a mesma perspectiva conceitual unilateral. Um exemplo de documentos regulatórios é o Parecer 02/2014 - CAOPEduc ${ }^{8}$ (Centro de Apoio Operacional às Promotorias de Justiça da Criança e do Adolescente e da Educação), elaborado para o Departamento da Diversidade da Secretaria de Estado da Educação do Paraná pelo Grupo Dignidade, e também utilizado como referência pela Gerência de Educação em Direitos Humanos da SME de Curitiba. Esse documento, ao discutir a necessidade da legalização da inclusão do nome social de menores de 18 anos em documentos nas instituições de ensino, argumenta que crianças menores de 16 anos que são dependentes, precisam do consentimento e representação dos pais ou responsáveis para requerer a inclusão do seu nome social

[...] se os pais/responsável legal se recusarem a formalizar o pleito, apesar da vontade manifestada pelo aluno, devem ser aqueles orientados, se necessário também com o apoio da "rede de proteção à criança e ao adolescente" local, acerca dos potenciais malefícios advindos da não inclusão do nome social e, caso persista a recusa, o caso deverá ser encaminhado ao Ministério Público, de modo que seja avaliada a ocorrência de possivel "colisão de interesses" e a necessidade da tomada de medidas administrativas ou judiciais para assegurar a adoção da solução que melhor atenda os interesses da criança/adolescente (DIGIÁCOMO \& DINIZ, 2014, p. 11) .

\footnotetext{
${ }^{8}$ Documento intitulado "Nome Social para menores de 18 anos" elencado como texto referencial da SME.

${ }^{9}$ Grifo nosso.
} 
Vê-se que, como todos os referencias para a educação estão fundamentados na educação em direitos humanos, ou seja, com a perspectiva da construção social da identidade, aqueles pais de crianças menores de 18 anos que discordarem e não agirem de acordo com tal conceito de gênero devem ser orientados "acerca dos potenciais malefícios advindos da não inclusão do nome social" e avaliada "a necessidade da tomada de medidas administrativas ou judiciais". Visivelmente os documentos oficiais, que fundamentam sua concepção de identidade de gênero na construção social, buscam induzir pais e responsáveis a assumir sua perspectiva e assim, acolher desejos e vontades dos menores, sem nenhuma investigação sobre motivações, perspectivas e a imaginação da criança e do adolescente sobre a mudança do nome social. Com isso, crianças e adolescentes ficam à mercê de teorias que desejam referendar uma agenda de poder e para isso necessitam de números, casos e fatos. A escola é o campo aberto dessa batalha, um lugar onde a dúvida, a insegurança individual do ser convive com a descoberta de caminhos para si e para a sociedade.

Diante da diversidade de concepções sobre a formação da identidade apresentadas nesta investigação, percebe-se que tais instruções e pareceres colocam-se em posição de árbitro do que é melhor para o outro, segundo sua particular visão de mundo. Se fosse o contrário, um parecer com a perspectiva biológica ou metafísica arbitrando sobre todos os outros, também seria evidente o menosprezo à pluralidade de visões de mundo e à liberdade dos pais orientarem seus filhos. É indiscutível, neste ponto de vista, que antes da presença da discussão sobre a diversidade de concepções identitárias, imperou, historicamente, a concepção binária e consequentemente o desamparo as demandas daqueles que não partilhavam desta concepção. O desequilíbrio representativo das diversas correntes conceituais que prejudicava uns, inverteuse e passou a prejudicar outros. Nesse sentido, cabe ainda questionar sobre a possibilidade ou a impossibilidade em acolher uma multiplicidade de concepções em um mundo cada vez mais múltiplo e diverso.

\section{A caminho de uma reflexão conclusiva: a necessidade de justiça e equidade para todos}

Diante de tal contexto é preciso questionar sobre a garantia de justiça e pluralidade para todos os envolvidos no processo educativo de crianças e adolescentes. Mas, qual seria o caminho para que a sociedade estabeleça a liberdade dos cidadãos e assegure, de fato, a pluralidade nesta questão? Pensar em justiça e equidade em termos de acolhimento de uma pluralidade de concepções de mundo, nos remete à filosofia política de John Rawls. Tendo 
como pano de fundo sua concepção de justiça, apresentada na obra Uma Teoria da Justiça (1997), pode-se tentar enfrentar à questão. A partir da questão: O que é uma sociedade justa? Rawls busca esclarecer quais os princípios fundamentais para se estabelecer uma sociedade que leve em conta valores individuais e sociais, porém sempre considerando a liberdade e a igualdade. $\mathrm{O}$ interesse em responder a questão de identidade de gênero, levando em conta a teoria rawlsiana, é justamente considerar que indivíduos possam ter a liberdade e a igualdade de tratamento no conjunto social. Ele afirma que "os planos dos indivíduos precisam se encaixar uns nos outros para que as várias atividades sejam compatíveis entre si e possam ser todas executadas sem que as expectativas legítimas de cada um sofram frustrações graves" (Rawls, 1997, p. 6).

Um dos pressupostos fundamentais para se compreender sua teoria é o reconhecimento do fato do pluralismo e de diversas concepções de Bem, pois a sociedade não comunga de uma única doutrina de Bem. Isso marcaria uma ruptura com a concepção de Bem Supremo. A filosofia política clássica conceituava o bem supremo (St. Agostinho, Cidade de Deus) como modelo para o homem. No entanto, a compreensão moderna de política, concebe que não é mais possível estabelecer o Bem Supremo. Os teóricos modernos, como Maquiavel e Hobbes, partem do pressuposto que o Bem não é compartilhado pelos indivíduos (Araújo, 2003).

Assim, é preciso considerar outros princípios que possam unir os humanos em uma mesma sociedade. O problema passa a ser o estabelecimento dos princípios de justiça que poderiam regular a coexistência de membros, cujos pensamentos e doutrinas, divergem uns dos outros. Segundo Rawls

Nos casos em que as regras de determinada parcela de uma instituição são conhecidas apenas por aqueles que pertencem a ela, podemos supor que há um entendimento de que essas pessoas podem criar regras para si próprias conquanto que essas regras sejam destinadas a atingir finalidades aceitas de forma geral e que os outros não sejam afetados negativamente (RAWLS, 1997, p. 59).

Partindo do pressuposto de que um dos problemas da filosofia política moderna é a legitimidade do poder político, pois como não pode mais ser considerado aquele emanado do Divino, necessita-se estabelecer as relações entre os humanos em outros termos, ou seja, através de acordos e contratos. A teoria contratualista de sociedade é um horizonte que pode ser concebido como fundamento nas relações sociais. Um dos aprendizados mais dolorosos e difíceis no processo de modernização da sociedade seria a convivência e tolerância de 
divergências profundas acerca de algo que seja mais essencial que a política, mas que precisa da política para sobreviver: o sentido último da existência humana. Segundo Rawls (1997), os filósofos antigos pensavam que a ética e a política eram disciplinas que tratavam desse problema fundamental: quais são os fins últimos que nós buscamos com nossas ações? Porém, quando se busca a concepção de excelência humana e virtudes para se chegar a essa excelência, a tendência é divergir, surge um enorme pluralismo de concepções de virtude.

A contraposição do pluralismo seria a opressão: quando um poder político tenta fazer com que seus cidadãos comunguem de uma concepção unívoca acerca do bem. A analogia que se pode fazer, com a opção teórica sobre identidade de gênero pelo Estado, fomentaria os mesmos conflitos. O problema agora, segundo Rawls, seria como estabelecer princípios de justiça em meio a diversidade e conflito de opiniões sobre o que seja o sentido último da existência humana. Para se fazer filosofia política se deveria partir desse pressuposto. Outro pressuposto para a compreensão da teoria de Rawls é o reconhecimento de todos os membros da sociedade como seres racionais (escolher fins e metas e mudar sua concepção caso queira) e razoáveis, duas capacidades morais intrínsecas aos indivíduos, que buscam esclarecer e realizar sua própria noção de Bem. Junto com essas capacidades, Rawls diz que cada cidadão é capaz de respeitar os termos equitativos da cooperação social. $\mathrm{O}$ fato de que eu eleja meus fins não me dá o direito de pensar que na realização dos meus fins, os fins dos outros não podem ser realizados, ou que sejam obstáculos aos meus. O problema da convivência em sociedade não seria a eliminação dos fins de cada um e sim, da capacidade de conjugar o livre arbítrio de cada um dentro de uma lei universal da liberdade que todos possam compartilhar (Araújo, 2003).

Com isso, é possível pensar que a tese principal de Rawls seria uma possibilidade estratégica para dirimir e viabilizar a coexistência e o equilíbrio de poder político dos cidadãos em seus diferentes modos de vida e concepções do Bem, e um desses seria a de formação de identidade. No entanto, sua tese parte do princípio de que só poderá ser realizada em ambientes e Estados democráticos, pois apenas nesses ambientes é possível estabelecer a tolerância e o respeito à alteridade. Rawls elabora uma complexa malha para explicar como poderíamos aceitar posições alheias sobre princípios de justiça, pois o acordo de princípios justos e equitativos asseguraria as diferentes posições individuais. Porém, isso não é objeto desta investigação. A teoria política de Rawls, que apresenta a necessidade de um consenso sobreposto para acolher múltiplas concepções do Bem, pode se transformar referência para refletir sobre o problema com a identidade de gênero. Sua exigência sobre a razoabilidade dos seres racionais envolvidos na discussão, acordos de princípios e tolerância de diferentes 
concepções do Bem, podem mostrar uma saída para os conflitos, pois se todos insistirem que sua posição individual seja universalizada não haveria como ordenar tais desejos. Estabelecer que a razoabilidade e igualdade de condições seja a métrica da discussão parece o mais razoável.

Portanto, quando, no decorrer desta investigação, percebe-se que o Estado opta por uma concepção teórica sobre a formação da identidade de gênero, não acolhendo outras, nem estabelecendo um debate sobre os efeitos coletivos de tal direção, confirma-se que não houve considerações conceituais mais largas na fundamentação das políticas públicas. Certamente, não é o primeiro e não será e o último entrave conceitual inegociável para diferentes setores da sociedade, pois poucos estão dispostos a entrar no processo democrático que envolve a definição de princípios e concepções a este respeito. Ordens religiosas que buscam referendar suas concepções, instituições políticas e a sociedade que resiste com a cultura e a história precisam estabelecer os limites para a atuação na escola, pois de Simone de Beauvoir até a Eva dos cristãos há um longo caminho percorrido, seja religioso, histórico, cultural e social. Tais conflitos não se dissiparão brevemente, porém a tensão parece interessante para manter a discussão viva. Se a filosofia política já elaborou questionamentos profundos sobre a natureza humana e propôs algumas estratégias, agora cabe um convite a discutir os impactos de tais teorias no ambiente escolar e esclarecer que os documentos oficiais estabelecem uma única posição, não teorizando outros valores e concepções no ambiente escolar. Que esses conflitos sejam um convite a discutir as múltiplas concepções de identidade de gênero na escola. É preciso compreender que a Escola é uma instituição que exerce grande influência na vida da criança e do adolescente, porém não pode estar em constante conflito com os valores pessoais, familiares ou sociais sob risco de perder sua credibilidade. Estabelecer um ambiente democrático e razoável sobre a questão da formação da identidade de gênero é acolher no interior da Escola a pluralidade de concepções e compreensões sobre identidade, sem restrições e unilateralismos. O que é preciso é uma efetiva vontade, política e social, de discutir as mais diversas formas de pensar e refletir sobre a condição humana no mundo.

\section{Referências}

ARAÚJO, Luís Bernardo. Jonh Rawls e o Renascimento do Liberalismo. Palestra em Vídeo. 2003. Disponível em https://www.youtube.com/watch?v=1esOeeHVDiI Acesso em 10/09/2019.

AUSTIN, John L. Quando dizer é fazer - Palavras e Ação. Porto Alegre: Artes Médicas, 1990. BARON-COHEN, Simon. Diferença essencial: a verdade sobre o cérebro de homens e 
mulheres. Tradução de Neusa Capelo. Rio de Janeiro: Objetiva, 2004.

BEAUVOIR, Simone. O segundo sexo: fatos e mitos. Tradução de Sérgio Milliet. $3^{\mathrm{a}}$ ed. - Rio de Janeiro: Nova Fronteira, 2016.

BUTLER, Judith. Problemas de gênero: feminismo e subversão da identidade. Tradução de Renato Aguiar. Rio de Janeiro: Editora Civilização Brasileira, 2003.

BRASIL, Plano Nacional de Educação em Direitos Humanos / Comitê Nacional de Educação em Direitos Humanos. - Brasília: Secretaria Especial dos Direitos Humanos, Ministério da Educação, Ministério da Justiça, UNESCO, 2007. 76 p. Disponível em https://mid-educacao.curitiba.pr.gov.br/2014/9/pdf/00045016.pdf Acesso em 22/09/2019.

CURITIBA, Plano de Formação Continuada da Rede Municipal de Curitiba. Prefeitura Municipal de $\quad$ Curitiba, $2019 . \quad$ Disponível $\quad$ em https://mideducacao.curitiba.pr.gov.br/2019/7/pdf/00228626.pdf Acesso em 28/09/2019.

DIGIÁCOMO, Murillo José \& DINIZ, Hirmínia Dorigan de Matos. Parecer 02/2014 CAOPEduc (Centro de Apoio Operacional às Promotorias de Justiça da Criança e do Adolescente $\quad$ e da Educação), $2014 . \quad$ Disponível $\quad$ em https://mideducacao.curitiba.pr.gov.br/2014/9/pdf/00045012.pdf Acesso em 20/09/2019

KIMURA, Doreen. Sex Differences in the Brain: Men and women display patterns of behavioral and cognitive differences that reflect varying hormonal influences on brain development. Scientific American. $1999 . \quad$ Disponível em http://www.ucd.ie/artspgs/langimp/genderbrain.pdf Acesso em 29/06/2019.

KUHNEN, Tânia A. É possível dizer algo novo sobre essencialismo de gênero? Resenha. Universidade Federal de Santa Catarina. Estudos Feministas, Florianópolis, 21(1): 395-412, janeiro-abril, 2013.2 Disponível em http://www.scielo.br/scielo.php?script=sci_arttext\&pid=S0104-026X2013000100025 Acesso em 01/07/2019.

OLIVEIRA, Manfredo Araújo de. Reviravolta linguístico-pragmática na filosofia contemporânea. Ed. Loyola. $2^{\mathrm{a}}$ Ed., 2005. Disponível em https://books.google.com.br/books?id=MdyZgbHCZ64C\&pg=PA52\&lpg=PA52\&dq=T EORIA+REALISMO+SEM\%C3\%82NTICO\&source=bl\&ots=vCpirjcbxq\&sig=RDnkrfs LINSyPaNMAD4d3Y2AreY\&hl=ptBR\&sa=X\&ved=2ahUKEwjk2rOyl6rdAhUGhpAKHTk KALgQ6AEwCXoECAIQAQ\#v=o nepage\&q\&f=true Acesso em 02/02/2019.

ONU BRASIL, Glossário de termos do Objetivo de Desenvolvimento Sustentável 5: Alcançar a igualdade de gênero e empoderar todas as mulheres e meninas. Org. Haroldo Machado Filho. Organização das Nações Unidas, 2016. Disponível em https://nacoesunidas.org/wp-content/uploads/2017/06/Glossario-ODS-5.pdf Acesso em 20/09/2019.

RAWLS, John. Uma teoria da justiça. Trad. de Almiro Pisetta e Lenita M. R. Esteves. - São Paulo: Martins Fontes, 1997. 
VERSALDI, Giuseppe Card. \& ZANI, Arciv. Angelo Vincenzo. Maschio e Femmina Li Creò: Per Una Via Di Dialogo Sulla Questione Del Gender Nell'educazione. Congregação para a Educação Católica. 2019. Disponível em

http://www.educatio.va/content/dam/cec/Documenti/19_0996_ITA.pdf Acesso em 14/07/2019

WITT, Charlotte. The Metaphysics of Gender. Oxford; New York: Oxford University Press, 2011. Disponível em http://eltalondeaquiles.pucp.edu.pe/wpcontent/uploads/2016/08/Studiesin-Feminist-Philosophy-Charlotte-Witt-TheMetaphysics-of-Gender-Studies-in-FeministPhilosophy-Oxford-University-PressUSA-2011.pdf Acesso em 22/05/2019. 